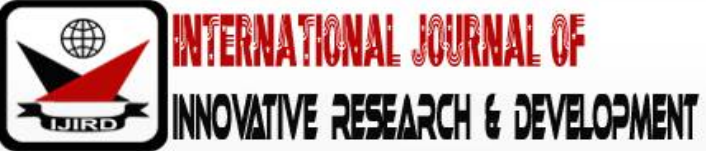

ISSN 2278 - 0211 (Online)

\section{Bridging Communication Barrier between Deaf-Dumb and Normal Persons via Mobile Phones Technology}

\author{
Bulus P. Bala \\ Lecturer, Department of Computer Science, Federal College of Education, Yola, Nigeria \\ Mohammed Umaru \\ Lecturer, Department of Computer Science, Federal College of Education, Yola, Nigeria
}

\begin{abstract}
:
Deaf and dumb is a category of impairments that impaired one ear and ability to talk. People with hearing impairment are part of the society. Some were born with it while others got it either in their early age in life or lately as a result of one ailment or the other. The incredible thing about these people is that they can learn and do everything that people without impairment do. They put effort to learn how to read and write using the traditional method of learning in addition to sign language which most of them understood well which most people without hearing impairment are not doing. Study try to find out why it is difficult for people without hearing impairment to communicate with the deaf and dumb? and whether or not Mobile phone applications will help in learning sign language and bridging communication barrier. 200 questionnaires were randomly administered to both lecturers and students in Federal College of Education, Yola (FCE) and State Polytechnic (SPY). Simple percentage was used to analyses the data. Result of the study revealed that most people find it difficult to communicate because they do not understand sign language and that it is stressful to use hands for spelling and communication. It also revealed that mobile phone application if use can help in learning and mastery of sign language and bridging communication barrier between deaf-dumb persons and people without the impairment. Recommendations were made on need for people without hearing impairment to learn sign language, sign language lesson be introduced in the school system at primary and secondary schools
\end{abstract}

Keywords: Sign Language and Spoken Languages are Equal in Status, Deaf-dumb and Their Ordeal, Importance of Mobile Phone Apps in Learning Sign Language

\section{Introduction}

Deaf and dumb is a category of impairments that impaired one ear and ability to talk. People with hearing impairment are part of our society. Some were born with it while others got it either in their early age in life or lately as a result of one ailment or the other. The incredible thing about these people is that they can learn and do everything that people without impairment are doing. It is because of this that many of them are enroll in a school system where learning take place in a conventional way. They put effort to learn how to read and write using the traditional method of learning in addition to sign language which most of them understood well which most people without hearing impairment are not doing. However, despite these efforts, communication between people with hearing impairment and those without is extremely difficult especially in a classroom that joins these people together. They cannot make friends with people without the impairment neither can they do so with their teachers/lecturers either within or outside the school environment because of the communication barrier.

School for adult, special and none formal education, is established to take care of people with special need. Most of its students are without any impairment and need to learn and master among other things sign language and sign language communication and there are no enough experts in this area handle that.

\subsection{Deaf-Dumb and Their Ordeal}

Deafness is a situation whereby someone's sense of hearing is non-functional. According to Ipkeazu and Iwuna (2010), deafness is the inability of ear to detect sound. One can simply put as complete lost sound as a result defect in ear drum which affects smooth communication especially between normal people and the deaf and dumb persons.

The number of deaf and dumb is continuously increasing (Alu, etal, 2018) and they are introverted in a closed society (Dalia Nashat, Abeer Noshor, Fowzyah AL-Swat and Reem El-Bailan, 2014). They need special love and care to able to blend with society and communicate with people who are not hear impaired. There seems to be no functional laws protecting the right of the physically challenged persons in the current educational dispensations. If there is, then their outright negligence. According to Onyemaech (2010), the effectiveness of any law lies in its applicability, implementation and enforcement mechanism. 
According (Nour, Banan and Mohammed, 2013), there is no enough specialist to teach deaf and dumb, that makes it high cost. Lack interest in learning sign language is contributing to the problem of communication. These deaf and dumb are enroll in normal school system where teaching and learning take place in a traditional way while others are not. Teachers especially in the higher institutions of learning such as universities, colleges and polytechnics fine it very difficult to effectively communicate with them. When there is one on one communication with a deaf person, there is tendency of using voice, demonstration or sign to convey a message. Dalia etal (2014) asserted that deaf-dumb can communicate with other people that are not in sign language, so they face serious problems in their daily lives. The category of deaf-dumb who do not have the chance of going through system are facing more challenge than those that had basic education.

\subsection{Sign Language and Spoken Languages Are Equal In Status}

Sign Language commonly develop in deaf communities, which can include interpreters and friends and families of deaf people as well as people who are deaf or hard of hearing themselves (Seshan, Madan, and sethna 2004).A sign language is a language which, instead of acoustically conveyed sound patterns, use visually transmitted sign patterns to convey meaning by simultaneously combining hand shapes, orientation and movement of the hands arms or body and facial (Seshan et al 2004). According to Dalia etal (2014), sign language is preferred among deaf-dumb as a way of communicating and depends on the finger spelling.

The simplest visual form of finger spelling is simulating the shape of letters in the air, or tactually tracing letters on hand. Finger spelling can use one hand such as in American Sign Language, French Sign Language and Irish Sign Language or two hands such as in British Sign Language (Morford, Jill MacFarlan and James and winter, 2003).

The United Nations (UN), describe sign language as a fully-fledged natural language, which are structurally distinct from the spoken languages. The UN makes it clear that sign languages are equal in status to spoken languages and obligates members states to facilitate the learning of sign language and promote the linguistic identity of the deaf community.

\subsection{Interaction with the Deaf and Dumb Is Not $\mathrm{A}$}

Many of the hearing-impaired persons are not educated. They cannot read or write. When communicating, there is tendency of using speech or sign which make it practically impossible to have conversation. In a school setting, educators in class during lesson delivery speak, demonstrate and give example to support a concept they present to students to understand and student's response in the same manner. Because most educators are not specialist in sign language, they will not be able to present concept adequately for the deaf-dumb among students without the hear impairment to comprehend. According Gao, Fang, Zhao and Chen, (2004), deaf-dumb need to distinguish things given them and identify their various forms and learn how to use them. When there is a way of teaching and learning through the use of mobile phone technology, communication will be interested and attractive.

\subsection{Important of Mobile Phone Apps in Learning Sign Language}

The greatest challenge of learning and using sign language in communication is not because it is hard to learn but because there are no enough specialists in sign languages to teach people. According to Nour, Bana, and Mohammed (2013), lack of specialist staff makes high cost.

Mobile phone technology will make it easy for people to learn and interact with deaf and dumb and also save costing. Since traditional way of communicating with the deaf-dumb is not attractive, Nour et al (2013), opined that using game and multimedia tools will make it more attractive. People will be able to learn by taking tutorial lesson, playing deaf-dumb sign game, quiz or chat with friends. Mobile apps will help achieve among other;

- One to learn at his/ her pace

- Communicate effectively without actually understanding sign language

- One to understand deaf-dumb around better and vice-versa

- Can be used any and any time

- People who develop this problem in at any stage in life can easily learn.

\section{Methodology}

The researchers adopted descriptive survey design for this study. This is because this approach does not involve alterations of variables but rather present them as they are.

\subsection{Instrument for Data Collection}

Data for this study is discrete. Instruments for data collection was designed by the researchers. A twelve items questionnaire which researchers designed and used to collect discrete data.

\subsection{Procedure for Data Collection}

Discrete data were collected through a "Bridging Communication Barrier between Deaf and Dumb and Normal People via mobile phone technology"; a twelve items questionnaire administered to both lecturers and students; those with impairment and those without impairment in Federal College of Education Yola, (FCE) and State polytechnic (SPY). A total of 200 questionnaires were administered. 198 were collected back from respondents which is $98 \%$ success. 


\subsection{Objectives}

- To find out why communication between deaf and dumb and normal people is difficult.

- To ascertain whether people use apps (window or mobile base) as an aid to enhance their learning of sign language

- Find out whether mobile phone apps for deaf and dumb if designed, will encourage communication and enhance learning of sign language by normal people.

\subsection{Statement of the Problem}

Deaf and dumb are people who because of impairments are not able to talk and find it difficult to communicate with other people. Some of them because they are privileged to have schooled are able to read and write in a conventional way. However, reverse is the case with people without hearing impairment in understanding sign language. People without hearing impairment are not using apps either window or mobile base to enhance their learning of sign language, bridge communication barrier, and to put themselves into world of these very important people in the society thereby not given them sense of belonging.

\subsection{Research Questions}

- Do normal people find it difficult to communicate effectively with the deaf and dumb?

- Do people use apps either window or mobile base to enhance their learning of sign language, and aid communication between deaf and dumb, and normal people effective without actually understanding sign language?

- Are there mobile apps available for sign language are for translation from sign to English and any of the official languages (Hausa, Igbo, and Yoruba) in Nigeria?

\section{Discussion}

\subsection{Research question1}

- Do normal people find it difficult to communicate effectively with the deaf and dumb?

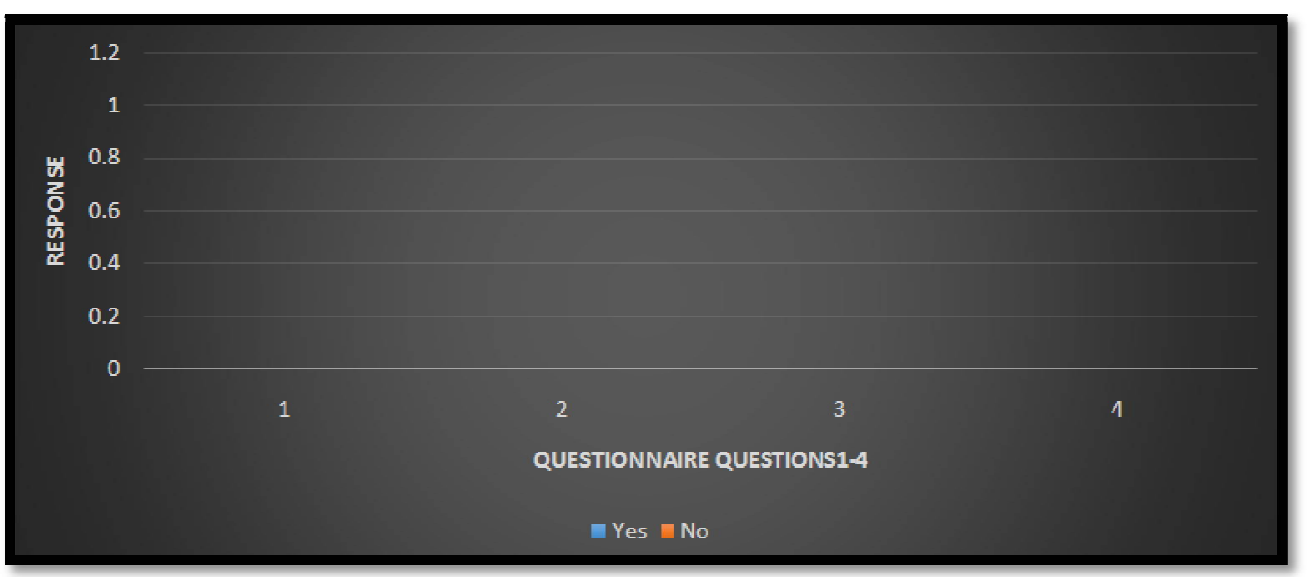

Figure 1: Percentage of People Responses for Question 1-4

To show whether people without hearing impairment finds it very difficult to communicate with hearing impairment persons, question 1-4 of the questionnaire was analyzed. Figure 2 showed that $80 \%$ of people without hearing impairment said yes that communication with people with hearing impairment is very difficult whereas $20 \%$ said no. $70 \%$ of the responded said it is stressful to use hands in communication with hearing impaired persons even if one has good mastery of sign language. People find it difficult to communicate with those with hearing impaired persons and that there is no any other means of communication except by the use of sign language as claimed by $100 \%, 80 \%$ responded respectively.

\subsection{Research Question2}

Do people use apps either window or mobile base to enhance their learning of sign language, and aid communication between deaf and dumb, and normal people effective without actually understanding sign language? 


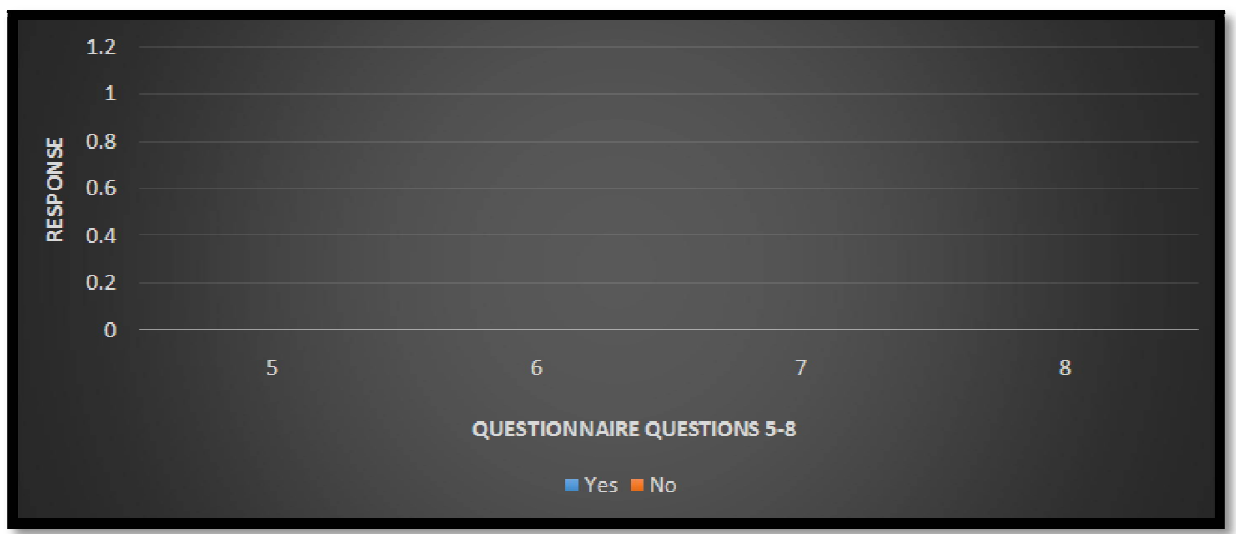

Figure 2: Percentage of Respondents' Responses for Question 5-9

An analysis into the research questions 2 shown above revealed from responded responses as indicated in Figure 2 showed that $70 \%$ of persons without hearing impairment do not make use of any mobile phone applications or television programmes in learning sign language skills. And 20\% said they are using mobile phone applications in improving efficiency in sign language whereas $80 \%$ said they are not using phone applications at all. Interestingly, all the responded said yes that mobile phones will aid communication with the hearing-impaired persons. $90 \%$ said mobile phone application if designed, help in communicating with hearing impaired persons

\subsection{Research Question3}

Are there mobile apps available for sign language are for translation from sign to English and any of the official languages (Hausa, Igbo, and Yoruba) in Nigeria?

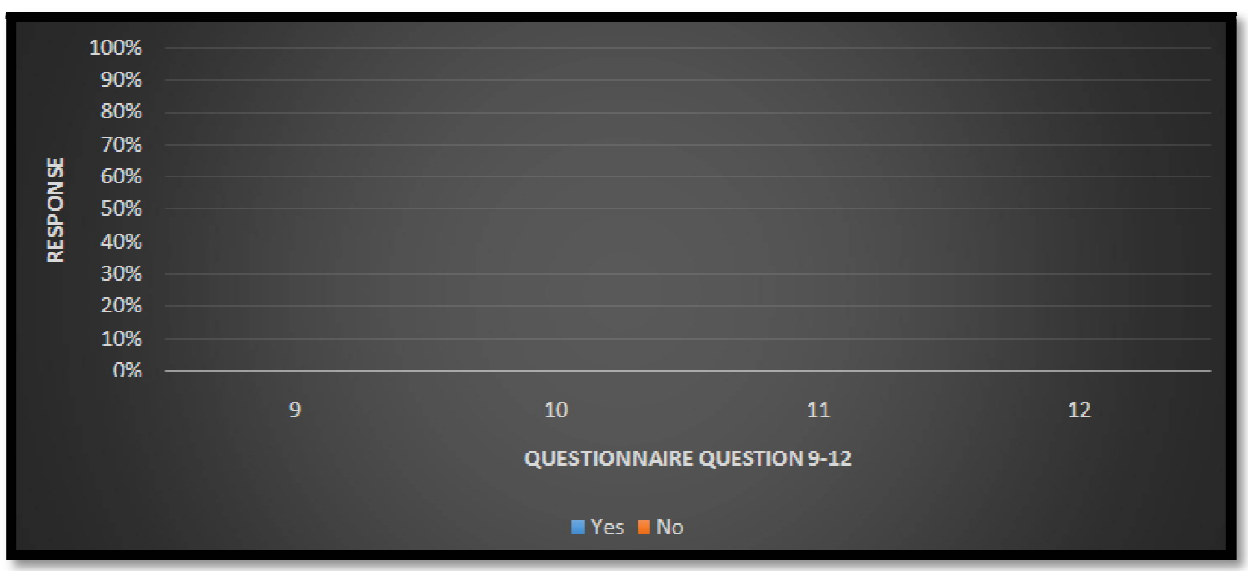

Figure 3: Percentage of People Responses for Question 10-12

An analysis into the research questions 3 shown above revealed from respondents' responses as indicated in Figure 3 showed that $50 \%$ of persons without hearing impairment do not make use of any mobile phone applications or television programs in learning sign language skills. Most responded believed that lack of mobile apps designed to aid communication with the hearing-impaired persons is affecting communication. All of respondents (100\%) said mobile phone apps designed for deaf-dumb communication will enhance mastery of sign language and communication with others. Also, almost all respondents (90\%) yes that mobile phone app for deaf and dumb if designed as a virtual deaf and dumb can aid mastering of sign language.

Findings

Based on the discussion on the twelve items questionnaire of research questions, the following findings and recommendations were made as follows:

- Persons without hearing impairment find it difficult to chat with the deaf and dumb persons because they do not comprehend sign language and there is no any other means of communicating with them except through sign language.it also find out that people without hearing defect do not used any medium to learn sign language and few that does, opined that it is stressful to used hand in communicating.

- No mobile phones app available for learning sign language and for translations into either, Hausa, Yoruba and Igbo. For that, they do not used app or any media to learn and master communication with deaf-dumb.

- All respondents agreed that mobile phones apps for communication will encourage learning and mastering communication

\section{Conclusion}

Mobile applications for learning sign language communication poise a great advantage to people to easily learn at their paces anywhere. Hence the need for people without hear impairment and most importantly students of special 
learning education to use mobile phone applications for learning sign language and for communication as an aid to mastery of sign language. By so doing, communication gab will be bridged and deaf and dumb around will a have sense of belonging.

\section{Recommendations}

Based on our findings, recommendations were made as follows:

- People without hearing defect should endeavor to learn sign language and sign language by so doing language communication barrier will be bridged. It will in turns give sense of belong to the impaired persons.

- Government should lease with expert from higher institutions of learning on the need to develop Mobile phone apps for learning deaf-dumb communication with focus on translating sign language into English, Igbo, Hausa and Yoruba etc.to ease mastering of sign language.

- Special education students should use apps learning sign language available as a matter of necessity to serve as learning aid for improvising communication since most of these students are without hearing impairment.

- There is need to introduce sign language lessons in our school system especially at the primary and secondary levels as pupils and students at these levels can learn fast considering their ages.

\section{References}

i. Adeniji R. O.(2013);Our lives as deaf and dumb couple. Retrieved 6/4/2019 from https:/ / www.churchtimesnigeria.net/ our-lives-as-deaf-and-dumb-couple/

ii. Dalia N., ABeer S, Fowzyah A., Reem A.(2014), AN ANDROID APPLICATIONTO AID UNEDUCATED DEAF-DUMB PEOPLE. International Journal of Computer science and Mobile Applications, vol2.

iii. Ikpeazu V., Onwuana ME (2010). Hearing impairment.In Obbue RM Obani TC. Abosi,OC(eds), Special Education: a reading text.Ibadan: Heinemann Educational books.

iv. Nour E.M,Bana Y.M.T., Moahmmed A. H.,(2013), Multimedia Education System for Deaf and Hear Impairment Children. International Arab Conference on Information Technology

v. Obaski (2018), Sign Languages Day: Obaseki pledges support for people with special needs . Retrieved 6/ 4/ 2019 at: $\quad$ https:// www.vanguardngr.com/ 2018/ 09/ sign-languages-day-obaseki-pledges-support-for-people-withspecial-needs

vi. Obinna Odogwu, (2017), Even the deaf hear discrimination: Nigerian deaf teachers lament neglect. Retrieved 6/ 4/2019 at https:/ / www.sunnewsonline.com/ even-the-deaf-hear-discrimination-nigerian-deaf-teachers-lament-neglect/

vii. W.Geo, G.Fang, D.Zhao, and Chen Y.(2004), "Transition Movement Models for Large Vocabulary Continuous Sign Language Recognition", Proc. Int'l conference Automatic Face snd Gesture Recognition. Pp553-558.

viii. Zeshan U., Madan M., Vasishta, Sethna M.,(2004), "Implementation of India Sign Langauge in Education Settings"vol15, Asia Pacific Disability Rehabilitation Journal. Pp15-35 